\title{
The ultra-low-frequency magnetic disturbances associated with earthquakes*
}

\author{
Masashi Hayakawa ${ }^{1,2,3,4, \star} \quad$ Yasuhide Hobara ${ }^{2,5}$ \\ Kenji Ohta $^{6}$ and Katsumi Hattori ${ }^{7}$ \\ ${ }^{1}$ Advanced Wireless Communications Research Center, The University of Electro-Communications, \\ 1-5-1 Chofugaoka, Chofu Tokyo 182-8585, Japan \\ ${ }^{2}$ Research Station on Seismo Electromagnetics, The University of Electro-Communications, \\ 1-5-1 Chofugaoka, Chofu Tokyo 182-8585, Japan \\ ${ }^{3}$ Hayakawa Institute of Seismo Electromagnetics, Co. Ltd., Incubation Center, The University \\ of Electro-Communications, Chofu Tokyo182-8585, Japan \\ ${ }^{4}$ Information Systems Corp., Earthquake Analysis Laboratory, Kita-Aoyama 2-14-42-305, \\ Minato-ku Tokyo 107-0061, Japan \\ ${ }^{5}$ Graduate School of Informatics and Engineering, The University of Electro-Communications, \\ Chofu Tokyo 182-8585, Japan \\ ${ }^{6}$ Department of Electronic Information, Chubu University, 1200 Matsumoto-cho, Kasugai \\ Aichi 487-8501, Japan \\ 7 Faculty of Science, Chiba University, 1-33 Yayoi, Inage Chiba 263-8522, Japan
}

\begin{abstract}
The ultra-low-frequency (ULF) electromagnetic emission is recently recognized as one of the most promising candidates for short-term earthquake (EQ) prediction. This paper reviews previous convincing evidence on the presence of ULF emissions before three major EQs. Then, we present further statistical study on the ULF occurrence, our networks of ULF monitoring in different spatial scales in Japan and finally we present several signal processings to identify the seismogenic emissions by showing latest results for recent large EQs.
\end{abstract}

Key words: seismogenic ULF emission; earthquake prediction; magnetic sensor; signal processing CLC number: P315.72 ${ }^{+} 1$ Document code: A

\section{Introduction}

Different electromagnetic phenomena are reported to take place in a wide frequency range prior to an earthquake (EQ) (Hayakawa and Fujinawa, 1994; Hayakawa, 1999; Hayakawa and Molchanov, 2002; Molchanov and Hayakawa, 2008), and these precursory seismoelectromagnetic effects are expected to be useful for the EQ prediction and the associated mitigation of EQ hazards. Basically there are two principal methods for observing EQ signatures (Uyeda et al., 2009; Hayakawa

\footnotetext{
* Received 13 May 2011; accepted in revised form 24 July 2011; published 10 December 2011.

† Corresponding author. e-mail: hayakawa@whistler.ee.uec.ac.jp

(C) The Seismological Society of China and Springer-Verlag Berlin Heidelberg 2011
}

and Hobara, 2010). The first is the direct observation of electromagnetic emissions (natural emissions) emitted from the lithosphere and the second is to detect indirect seismic effects appearing in the atmosphere and ionosphere (Molchanov and Hayakawa, 2008). The former method is based on the idea that natural emissions are radiated from the EQ hypocenter due to the generation of electric currents by some tectonic effect during the preparation phase, and one of the typical examples belonging to this category, is the ultra-low-frequency (ULF, frequency less than $10 \mathrm{~Hz}$ ) electromagnetic emission. The second is based on the concept that there appear the anomalies in the atmosphere and ionosphere due to the seismicity, leading to the abnormal propagation of the pre-existing transmitter signals (detected as anomalies in the received amplitude and phase). 
This review deals with the ULF magnetic field variation as the direct consequence of precursory lithospheric effect. Even though the radio emissions are generated as a pulse in the EQ hypocenter, higher frequency components cannot propagate over long distances in the lithosphere due to severe attenuation, but only ULF waves can propagate up to an observation point near the Earth's surface with small attenuation. This is the most important advantage of seismogenic ULF emissions. A few good reviews have been recently published on these seismogenic ULF electromagnetic emissions, including Hayakawa et al. (2007), Fraser-Smith (2009), Kopytenko et al. (2009) and Hayakawa and Hobara (2010). This paper summarizes the current state of art of seismogenic ULF emissions based on the results for previous three major EQs and other EQ events, including the general characteristics of seismogenic emissions, signal processing techniques and future directions.

\section{Three major ULF events}

There have been reported three reliable events for the ULF magnetic field variations prior to the major EQs: (1) Spitak EQ in Armenia (8 December 1988, M6.9) (Molchanov et al., 1992; Kopytenko et al., 1993), (2) Loma Prieta EQ in California, USA (18 October 1989, M7.1) (Fraser-Smith et al., 1990), and (3) Guam EQ in Japan (8 August 1993, M8.0) (Hayakawa et al., 1996). Table 1 summarizes the physical parameters of these EQs and also the properties of ULF emissions for these three EQs. The epicentral distance is $129 \mathrm{~km}$ for (1), $7 \mathrm{~km}$ for (2) and $65 \mathrm{~km}$ for (3). The Loma Prieta EQ happened very close to the observing station, so that it is better for us to indicate the results for this EQ as a typical example. Figure 1 illustrates the temporal evolution of ULF magnetic field (one horizontal component, frequency $f=0.01 \mathrm{~Hz}(10 \mathrm{mHz})$, i.e. period $T=100 \mathrm{~s})$ just around the EQ date. It indicates that the magnetic field increases for about one week 5-12 days before the EQ, followed by a quiet period and a sharp increase one day before the EQ (especially an abrupt increase 3-4 hours before the EQ). Very significant changes in ULF magnetic field were also observed for other two EQs (Molchanov et al., 1992; Hayakawa et al., 1996), which was a stimulus to the extensive research on the relationship of ULF emissions with EQs.

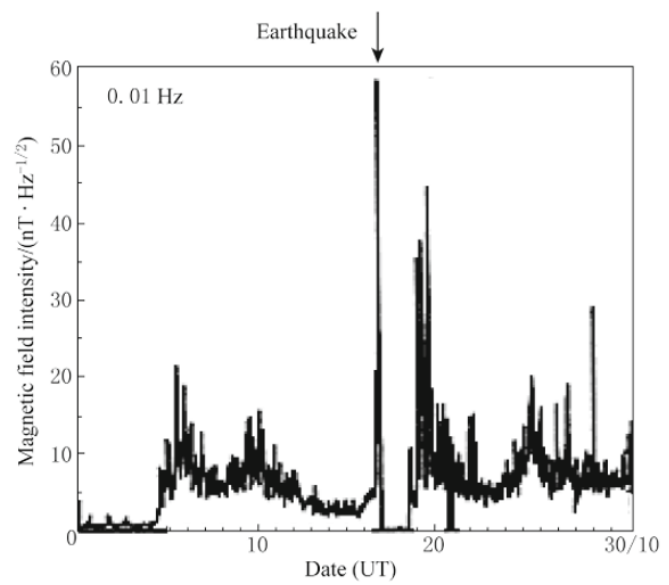

Figure 1 Temporal evolution of geomagnetic variation (only one horizontal component) for the Loma Prieta earthquake $(f=0.01 \mathrm{~Hz}, 10 \mathrm{mHz})$ on October 18, 1989 (after Fraser-Smith et al., 1990).

Table 1 Three major ULF events

\begin{tabular}{|c|c|c|c|c|c|c|}
\hline Earthquake & $M$ & $\begin{array}{l}\text { Depth } \\
\text { /km }\end{array}$ & $\begin{array}{c}\text { Epicentral } \\
\text { distance } / \mathrm{km}\end{array}$ & Analysis method & Characteristics & References \\
\hline $\begin{array}{l}\text { Spitak earthquake } \\
\text { in } 1988\end{array}$ & 6.9 & 6 & 129 & $\begin{array}{c}\text { Amplitude } \\
\text { (3 components) }\end{array}$ & $\begin{array}{l}\text { An increase } 3-4 \text { days before } \\
\text { the EQ, and a sharp increase } \\
\text { four hours before the EQ. } \\
\text { Gradual decrease to the } \\
\text { normal level in one month. }\end{array}$ & $\begin{array}{l}\text { Molchanov et al. } \\
\text { (1992), Kopytenko } \\
\text { et al. (1993) }\end{array}$ \\
\hline $\begin{array}{l}\text { Loma Prieta } \\
\text { earthquake } \\
\text { in } 1989\end{array}$ & 7.1 & 15 & 7 & $\begin{array}{c}\text { Amplitude } \\
\text { (Only one component) }\end{array}$ & $\begin{array}{l}\text { The first maximum one to } \\
\text { two weeks before the EQ. Then } \\
\text { a quiet period, an increase } \\
\text { a few days before the EQ, and } \\
\text { a sharp increase a few hours } \\
\text { before the EQ. Relaxation in a } \\
\text { few months. }\end{array}$ & $\begin{array}{l}\text { Fraser-Smith et al. } \\
\text { (1990), Molchanov } \\
\text { et al. (1992) }\end{array}$ \\
\hline $\begin{array}{l}\text { Guam earthquake } \\
\text { in } 1993\end{array}$ & 8.0 & 60 & 65 & $\begin{array}{l}\text { Polarization and } \\
\text { fractal method }\end{array}$ & $\begin{array}{l}\text { Abnormal increase in polarization } \\
\text { one month to a few days before } \\
\text { the EQ. }\end{array}$ & $\begin{array}{l}\text { Hayakawa et al. } \\
(1996,1999)\end{array}$ \\
\hline
\end{tabular}


Recently, the widely discussed observations of distinct ULF emissions prior to the Loma Prieta and Guam EQs have been called into question (Campbell, 2009; Thomas et al., 2009a, b), but the arguments against these signals are weak. They have just tried to correlate the signals with the geomagnetic activity, so that their arguments were not strong enough to deny the presence of precursory seismogenic ULF emissions.

\section{Correlation between ULF emis- sions and EQs}

Based on the results for the famous three major EQs in the previous section and for other EQs, Figure 2 is the summary on the occurrence of the EQ-related ULF activity in the form of EQ magnitude $(M)$ versus epicentral distance $(R)$ from a ULF magnetic station (Hattori et al., 2004; Hayakawa and Hattori, 2004; Molchanov and Hayakawa, 2008). Open and solid circles in the figure show an EQ with and without ULF anomalies, respectively. The dashed line indicates the empirical threshold $(0.025 R \leq M-4.5)$ for the appearance of anomalous ULF signals preceding large EQs. This figure demonstrates that ULF emissions could be observed about $70 \mathrm{~km}$ from the source region for an EQ with $M \geq 6$, and the detectable distance of ULF magnetic anomalies would be extended to about $100 \mathrm{~km}$ in

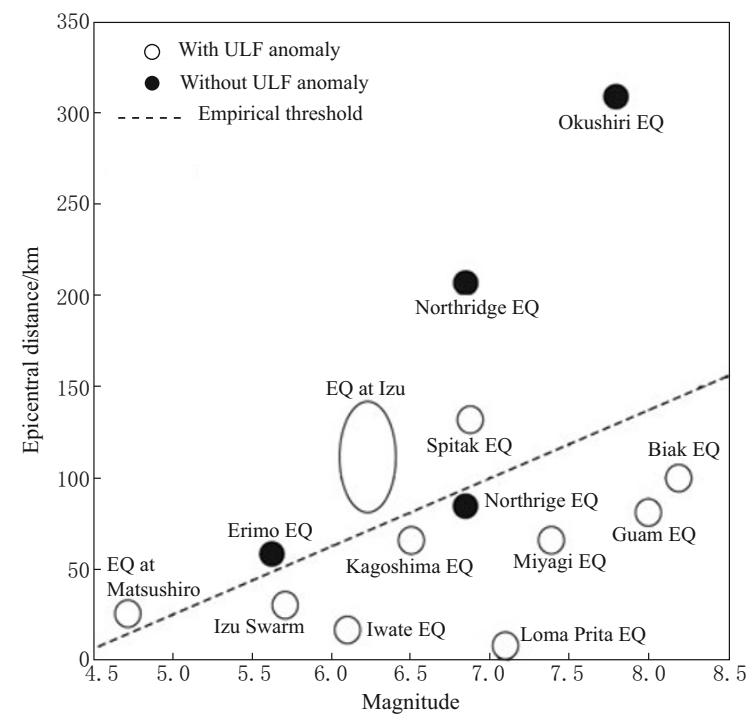

Figure 2 Summary of the seismogenic ULF emissions in the form of EQ magnitude $(M)$ and epicentral distance $(R)$. A open circle means the event with ULF anomaly, while a solid circle, the event without ULF anomaly. The empirical threshold is indicated by a dashed line $(0.025 R \leq M-4.5)$. the case of an EQ with $M \geq 7$. This empirical threshold gives us a useful hint on how to locate ULF sensors for the seismogenic studies.

A few exceptions to the empirical threshold obtained in Figure 2 have been recently reported. The first event is the ULF emissions observed for the NiigataChuetsu EQ happened at 17:56 JST on October 23, 2004 (with magnitude of 6.8 and depth of $10 \mathrm{~km}$ ) (Ohta et al., 2005). The ULF emissions with $f<0.1 \mathrm{~Hz}$ have been observed two to three weeks before the EQ at Nakatsugawa in Gifu prefecture, so that the epicentral distance is $230 \mathrm{~km}$. Another exception is for the Indonesia, Sumatra EQ on December 26 of the same year of 2004 (Ohta et al., 2007). The ULF emissions seeming to be associated with this huge (M9.2) EQ, were observed in the same observatory of Nakatsugawa. The corresponding epicentral distance is $6000 \mathrm{~km}$, and we have to mention that the depth of this EQ is shallow $(\sim 10 \mathrm{~km})$ again.

\section{Existing ULF networks in Japan}

It is important to predict EQs with $M \geq 6$ in a highly populated region to mitigate EQ disasters. Therefore, we decided to install a network of ULF magnetometers with high sampling rate to cover the Kanto (Tokyo) district with inter-sensor distances of about 70$80 \mathrm{~km}$. This spacing is consistent with the former empirical formula in Figure 2. Two types of magnetometers are adopted: torsion and induction types, and we measure three magnetic components $\left(B_{x}, B_{y}, B_{z}\right)$ at each station. Taking account of the existence of Kakioka Geomagnetic Observatory, Japan Meteorological Agency (JMA) (geographic coordinates: $36.2^{\circ} \mathrm{N}, 144.2^{\circ} \mathrm{E}$ ) as a reference station, we planned to set up stations to cover the area as shown in Figure 3. Circles in the figure indicate the distance of $60 \mathrm{~km}$ from the station (the circle from Kakioka observatory is also displayed). The details of Kanto ULF network are described in Hattori et al. (2004), Hayakawa (2006), and Molchanov and Hayakawa (2008).

As seen from Figure 3, a small L-shaped array has been composed with three torsion magnetometers, the distance of which is about $5 \mathrm{~km}$ at the western part of Izu peninsula and the southern part of Boso peninsula. With these arrays, we expect to develop a method to find the arrival direction of observed ULF waves. Both Izu and Boso peninsulas are seismic active regions, so that we consider it suitable for precise observation for direction finding of ULF anomalous signals by means of 
these arrays.

Another ULF/ELF network has been established in the central part of Japan (Chubu region), which consists of three observatories at Nakatsugawa (Gifu prefecture), Izu and Shinojima (an island in the Mikawa Bay,
Aichi). Three magnetic field components $\left(B_{x}, B_{y}, B_{z}\right)$ are measured by induction magnetometers at each station with the sampling frequency of $100 \mathrm{~Hz}$ (Hata et al., 2010), and the recording has started since March 2007. Figure 4 illustrates the relative location of these three

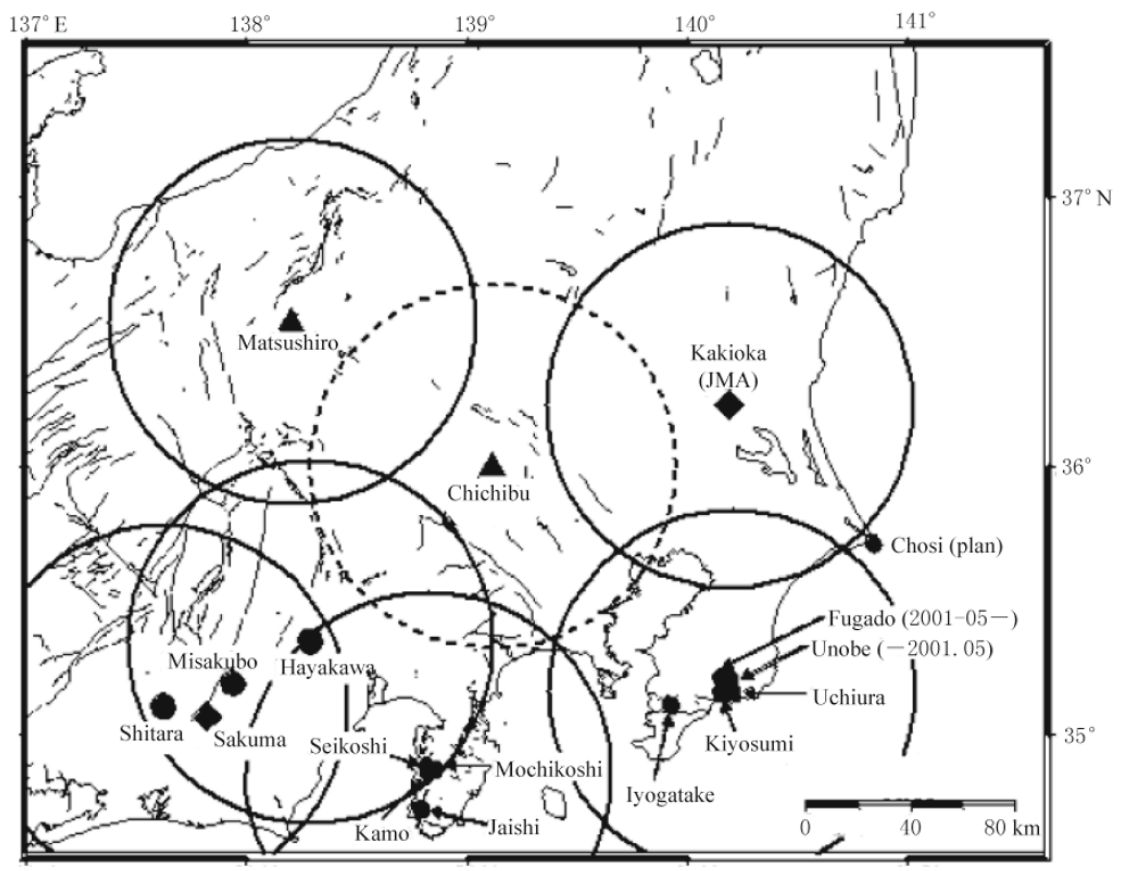

Figure 3 A ULF network in the Kanto (Tokyo) area. A triangle indicates the installation of an induction magnetometer and a circle, the torsion-type magnetometer. Kakioka observatory is equipped with induction magnetometers. A box indicates the fluxgate magnetometer. The main observatories are located at Izu peninsula, Bose peninsula, Kakioka, Chichibu, and Matsushiro.

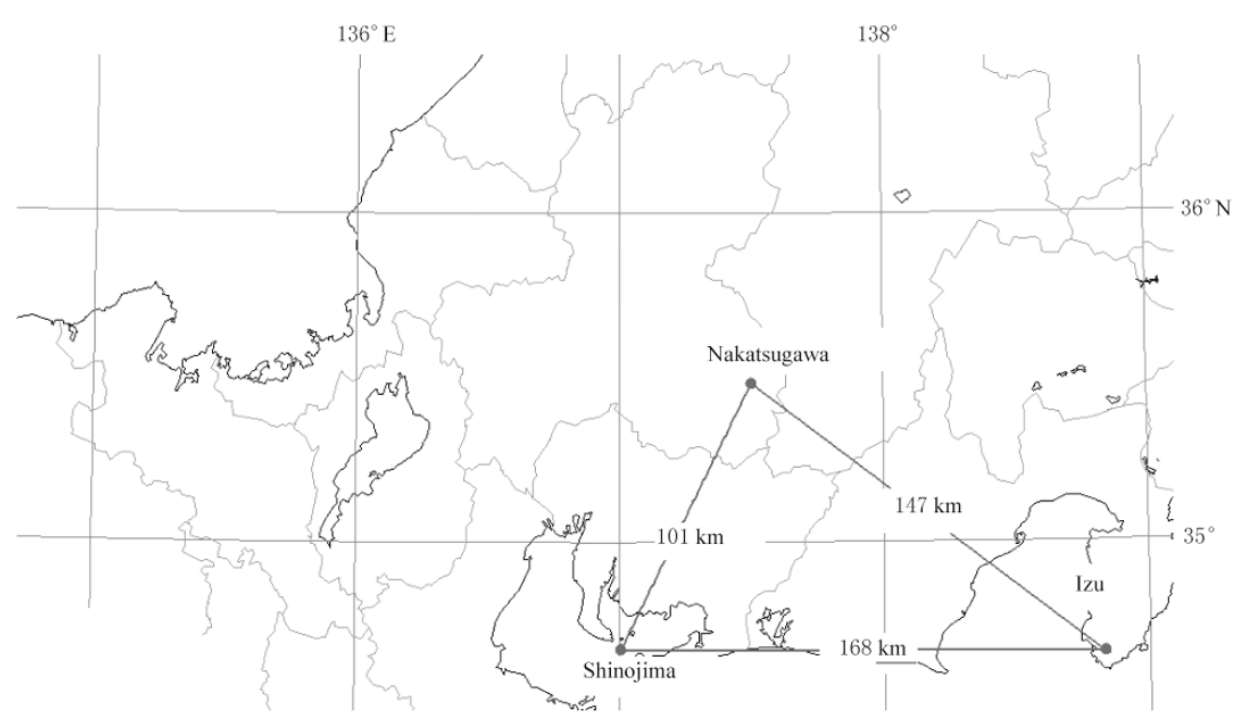

Figure 4 A map of Chubu region ULF/ELF network composing of three observatories (Nakatsugawa, Izu and Shinojima). Three magnetic field components $\left(B_{x}, B_{y}\right.$ and $\left.B_{z}\right)$ are measured at each station with sampling frequency of $100 \mathrm{~Hz}$. 
observatories in the Chubu district.

The final nationwide ULF/ELF network is going to work shortly. The ULF/ELF (with high sampling of 4 $\mathrm{kHz}$ ) has already been working successfully in Moshiri, Hokkaido for over one decade (Ando et al., 2005; Hobara et al., 2006). We measure two horizontal magnetic fields $\left(B_{x}, B_{y}\right)$ and one vertical electric field $\left(E_{z}\right)$ there. The second station for this nationwide ULF/ELF network has been just started at Kagoshima, Kyushu. The third station will be established in the Miyake island shortly, which will form a nationwide ULF/ELF network.

\section{Analysis methods of ULF mag- netic field variations}

Not only installing highly sensitive ULF sensors as described in the previous section (Kanto region, Chubu region and nation-wide area), but also carrying out different sophisticated signal processings are highly required to detect and identify weak seismogenic ULF emissions even in the noisy electromagnetic environment. Several useful signal processings have already been developed, some of which will be described below.

\subsection{Cumulative probability plots}

A few serious problems that must be overcome in the study of EQ signatures in the ULF data are the complexity of the background from other natural and man-made sources and the low probability of locating a sensor near the epicenter of a large magnitude EQ. Statistical analysis of the data may provide an important tool to address both of these problems, and a typical example for such statistical analyses is the cumulative probability plot for the ULF magnetic field (Koons et al., 2002).

Koons et al. (2002) applied this method to the ULF data observed at Seikoshi station in the Izu peninsula during the period of July through December 1999. They compared the distribution fluctuations of the Seikoshi data with those from sensors at Parkfield and Hollister, CA for the same time period and with distribution functions from a sensor at Corralitos, CA. The Corralitos data are from July to August 1989 prior to the Loma Prieta EQ (Figure 1 and Table 1) and from November to December 1989 after the EQ. They found that the Seikoshi and pre-EQ Corralitos data have similar distribution functions and that Parkfield and Hollister have similar distributions. However, those from Seikoshi and Corralitos are significantly higher below 50\% cumulative probability than those from Parkfield and Hollister. They may have attributed this difference to an emission with a steep spectral slope, but with a narrow range in magnetic field spectral density between $0.01 \mathrm{~Hz}$ and 2.0 $\mathrm{Hz}$.

\subsection{Polarization analysis}

As mentioned in section 5.1, the most important point for seismogenic ULF emissions is how to distinguish them from other various noises. Kopytenko et al. (1993) and Hayakawa et al. (1996) proposed the socalled polarization analysis, which measures the ratio of vertical magnetic field component to the horizontal components $S_{z} / S_{G}\left(S_{G}^{2}=S_{H}^{2}+S_{D}^{2}, H\right.$ and $D$ are two horizontal magnetic components and $z$, the vertical compornent). The principal idea of this polarization analysis is that while we expect that this ratio $S_{z} / S_{G}$ (polarization) is relatively small for the geomagnetic variation (or geomagnetic pulsations) from the ionosphere/magnetosphere, this ratio is considered to be considerably enhanced, $S_{z} / S_{G} \approx 1$ or even more for seismogenic emissions from the lithosphere by considering the Biot-Savart's law by a possible current source.

This polarization analysis was successfully used for the 1993 Guam EQ (Hayakawa et al., 1996), which showed an enhanced $S_{z} / S_{G}$ during one month before the EQ, indicative of the presence of seismogenic ULF emissions. Then, Hattori et al. (2002) studied the temporal evolution of $S_{z} / S_{G}$ for the 1997 Kagoshima EQs, who found an enhancement of the polarization just before the EQ. Recently Ida et al. (2008) have proposed an improved polarization method, which has enabled them to extract a ULF precursor to a moderate EQ in China.

\subsection{Principal component analysis}

When we have the ULF data observed simultaneously at multiple stations, we can distinguish a few noise sources by use of principal component analysis.

The principal component analysis was first applied to the ULF data during the Izu islands EQ swarm in 2000 (Gotoh et al., 2002), because we have small arrays consisting of 3-4 magnetometers in the Izu and Boso peninsulas as in Figure 3. A remarkable event from the Kanto ULF network is the $2000 \mathrm{Izu}$ islands EQ swarm. The seismic activity at Miyake island started to be active in the late June of 2000, and the volcano eruption started there. The activity continued not only at Miyake island, but also at its surroundings. By using the ULF data observed at close stations, for example, in the Izu peninsula (Seikoshi, Mochikoshi, and Kamo), we can have three sets of data, which enables us to separate three possible sources. Generally speaking, the ULF signal observed at a station, is a combination of a few effects: (1) geomagnetic variation of the magnetosphere 
(e.g., geomagnetic storms) due to the solar activity, (2) man-made noise, and (3) any other effect (including seismogenic emissions). The eigen-values $\lambda_{n}(n=1,2$, 3 ) of three principal components in the frequency range from $T=10 \mathrm{~s}$ to $T=100 \mathrm{~s}$ are traced by using the timeseries data. The analysis shows that the first principal component $\left(\lambda_{1}\right)$ is highly correlated with the geomagneric activity $\left(A_{p}\right)$. The second eigen-value $\left(\lambda_{2}\right)$ is found to have a period of 24 hours, with daytime maximum and nighttime minimum. This suggests that this noise is due to the human activity. We notice an enhancement in $\lambda_{3}$ from the middle March to the middle June (about a few months), followed by a quiet period (about one week before the first EQ) and by a sharp increase a few days before the first EQ. Similar sharp peaks are seen for the subsequent EQs with magnitude greater than 6.0. This general behavior seems to be in close agreement with Figure 1, which indicates that this variation is reflecting the crustal activity in this district. See the details in Gotoh et al. (2002).

\subsection{Inter-station transfer function (ISTF) method}

This method is an extension of the conventional transfer function, which is based on the comparison of the ULF data with those at a remote reference station located at a place with sufficiently low electromagnetic noise environment. By using the correlations of the variations at one current station with those at the reference station, we will be able to eliminate first the global effect (with scale of hundreds of $\mathrm{km}$ ) such as the solarterrestrial effect and then be able to detect the regional (with scale of a few tens of $\mathrm{km}$ ) or local effect (less than a few $\mathrm{km}$ ), that is, seismogenic effect (Hattori, 2004).

Takahashi et al. (2007) have made full use of this ISTF method when analyzing the time dynamics of short-term variability of geoelectrical potential differences and geomagnetic fields observed at a few stations (Kiyosumi, Uchiura, and Fudago) located in the southern part of Boso peninsula, one of the most seismoactive areas in Japan. Anomalous changes in electric and magnetic fields are observed in midnight on October 6,2002 . The anomalous signals observed on October 6 are different from those originated from the train and other cultural noises on the basis of the study on the preferred directions of geoelectric field. The investigation of simultaneous geomagnetic field changes suggests that the source of the change might be generated by an underground current because of the polarity patterns as observed at the above three stations.

\subsection{Direction finding}

Direction finding is a sophisticated radiophysical method to locate the ULF electromagnetic noise, that is, this technique is to estimate (or to infer) the position of radiating electromagnetic noise source by means of triangulation (Hayakawa and Ohta, 2006). It is of extreme importance to convince the people that the inferred position coincides with the epicenter of a future EQ. A few different principles are developed in the direction finding.

\subsubsection{Magnetic field gradient method}

The direction finding based on the magnetic field gradient is applied to ULF emissions for the abovementioned Izu islands EQ swarm (Kopytenko et al., 2002; Ismaguilov et al., 2002). We have used the same local array network consisting of, at least, three stations in the Izu and Boso peninsulas. By measuring the gradient of horizontal and vertical components of the magnetic field at different frequencies and separating a few possible sources from their temporal changes with respect to the EQ time, we can deduce the direction of azimuth of the seismogenic noise as normal to the observed gradient. By plotting the distribution of signal azimuths, we perform the triangulation of the seismogenic ULF emission from the Izu and Bose peninsula data. Figure 5 is the final result, which indicates that the noise source seeming to be attributed to the EQ swarm is located at the place to be expected.

\subsubsection{Goniometric method}

The goniometer is a conventional direction finding method (Hayakawa and Ohta, 2006), in which we assume a linearly polarized electromagnetic field and the ratio of amplitudes of two horizontal magnetic fields gives us the signal azimuth.

We apply this goniometric direction finding to the ULF emissions for a recent large Niigata-Chuetsu EQ on 23 October, 2004 by using the data from other observatory at Nakatsugawa of the Chubu ULF/ELF network. The magnitude and depth of this EQ are 6.8 and $10 \mathrm{~km}$. The three components of magnetic field $\left(B_{x}, B_{y}, B_{z}\right)$ are measured at Nakatsugawa by using the same induction magnetometers like at Izu and Boso peninsulas, but the importantly different point is that the waveform measurement is being performed in a wide frequency band with the sampling frequency of $100 \mathrm{~Hz}$. By estimating the temporal evolution of magnetic intensity $\left(B_{y}\right.$ component) in the frequency range $f<0.1 \mathrm{~Hz}$, we estimate the period when the signal intensity is extremely enhanced by $3 \mathrm{~dB}$ as compared with the monthly mean 


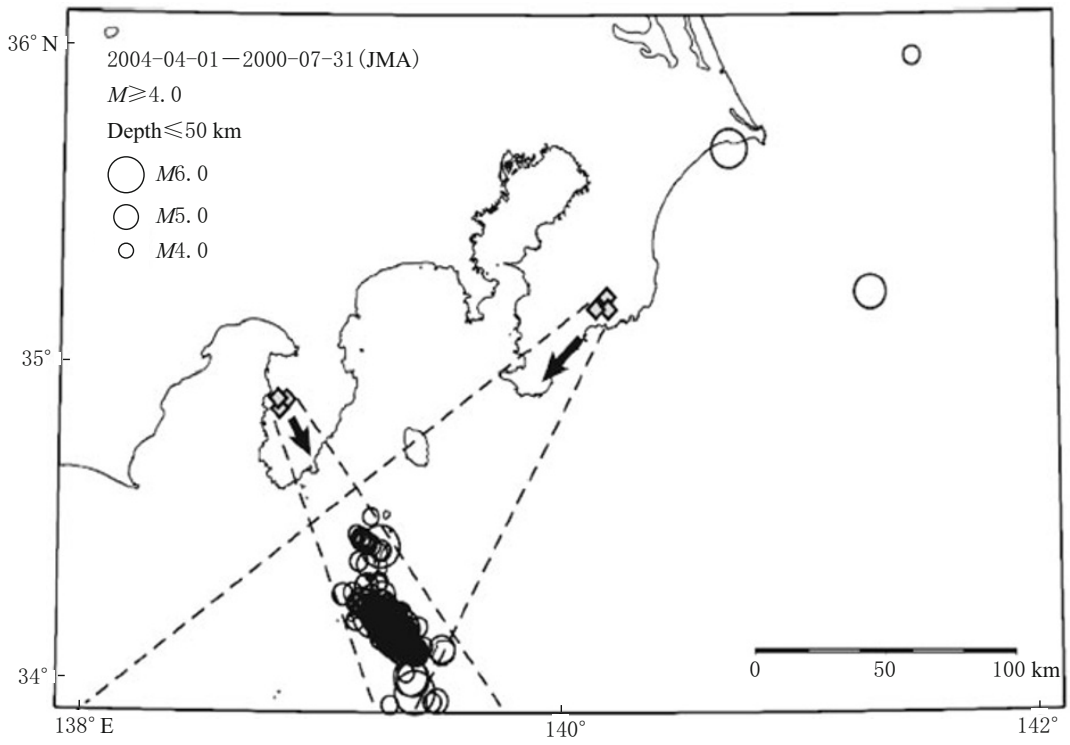

Figure 5 Triangulation of the seismogenic noise source by using the azimuths estimated from the Izu and Boso peninsula ULF arrays (after Kopytenko et al., 2002). The mean azimuth from Izu stations is indicated by an arrow, with its possible deviations from the mean azimuth indicated by two dotted lines. The same definition for the Boso peninsula.

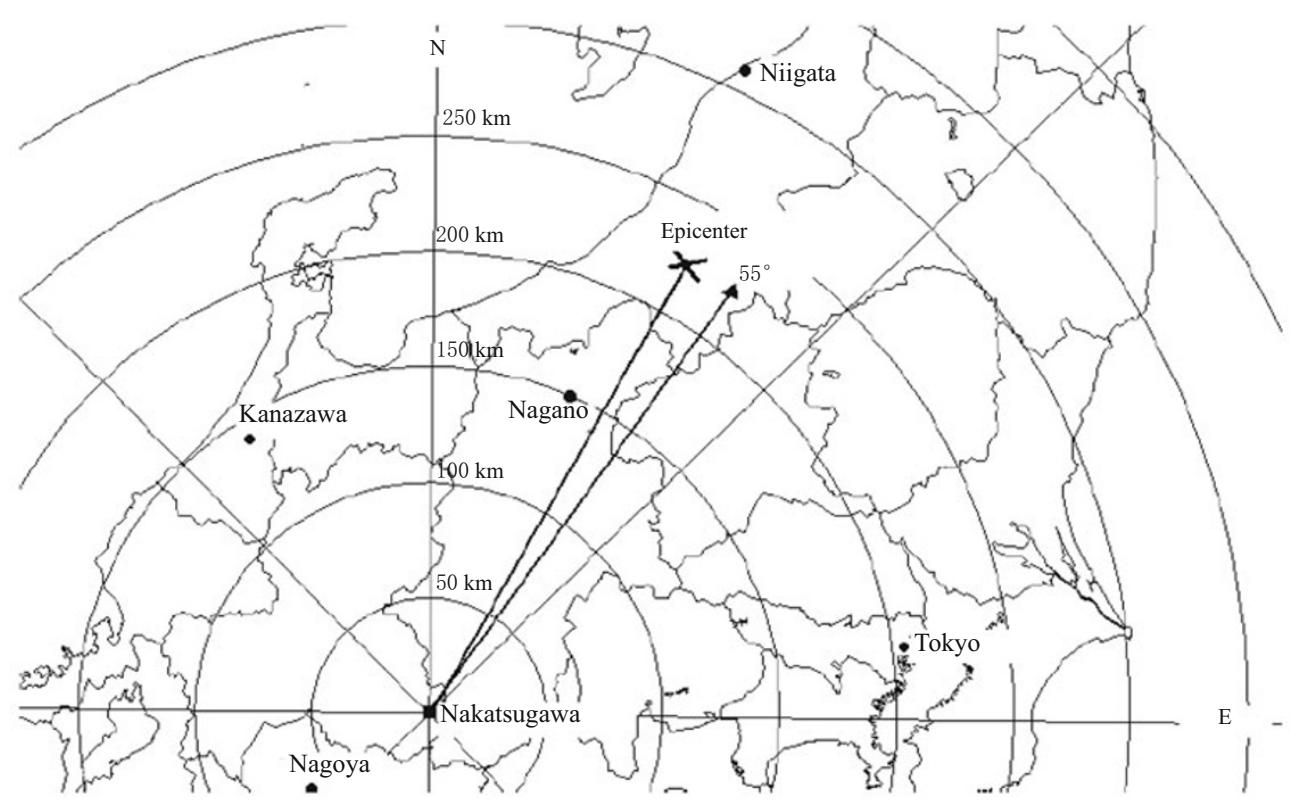

Figure 6 Goniometric direction (expressed by a thick line with an indication at the top of $55^{\circ}$ ) of seismogenic ULF noises during 2-6 October as seen from Nakatsugawa of the Chubu region network for the Niigata-Chuetsu EQ on 23 October, 2004 (after Ohta et al., 2005). The EQ epicenter is also indicated by a cross for the sake of comparison.

during several days from October 2 to October 6 (though not shown). This noise seems to be anomalous. However, we cannot conclude that this is associated with the EQ, even though it occurs about a few weeks before the EQ. Then, we performed the direction finding for this noise, and estimated the arrival azimuth by taking the ratio of $B_{x} / B_{y}$ for the emissions with anomalous amplitude during 2 to 6 October. The 
estimated azimuth (mean value) is indicated in Figure 6 . The azimuthal direction is $55^{\circ}$ from the East, which is consistent with the epicentral direction of the future EQ. This is indicative of a higher possibility that the noise is associated with the relevant EQ. See the details in Ohta et al. (2007).

\subsubsection{A new polarization ellipse method}

A new direction finding technique has been proposed by Dudkin et al. (2010), which is an application of the polarization ellipse technique. The principle is as follows. The magnetic field components corresponding to the spectral bands dominated by seismoelectromagnetic fields define the polarization ellipse plane, which, at any instant, contains the source of electromagnetic fields. A line of intersection of such defined polarization ellipse planes for distant observatories defines the source region.

This new direction finding has been applied to the ULF electromagnetic emissions observed at two distant stations in Koyna-Warna seismoactive region of west India (Dudkin et al., 2010). They have succeeded in approximating the magnetic-dipole configuration for the source and magnetic field components along the intersection lines, and suggested that the azimuth of the source is aligned in the NNW-SSE direction, which is well coincident with the orientation of nodal plane of the normal fault mechanism for the two largest EQs recorded during the campaign.

\subsection{Polarization ellipse and direction finding}

A useful analysis procedure has been presented by Schekotov et al. (2007) by using the ULF-ELF data. The magnetic field variations are measured at the Karimshino observatory (geographic coordinates: $52.83^{\circ} \mathrm{N}, 158.13^{\circ} \mathrm{E}$ ) in Kamchatka, Russia since June 2000, and three magnetic field components are measured with the three-component magnetometers with sampling frequency of $50 \mathrm{~Hz}$. The power spectral densities are calculated for the field components $(h, d$ and $z$ components), together with the cross-spectra of the horizontal components $\left(P_{h d}\right)$. First, the periodograms of polarization ellipse for 256 points samples $(\sim 5 \mathrm{~s})$ are calculated and then averaged over $30 \mathrm{~min}$ intervals. The parameters of polarization ellipse are estimated by the conventional procedure, such as ellipticity, sense of polarization, etc.

Based on the above analyses, Schekotov et al. (2007) have found that a wideband emission was observed about five days before an EQ and lasted until five days after the EQ. Also, seismogenic ULF/ELF emissions in the frequency range of $4-6 \mathrm{~Hz}$ are found to have an enhanced $P_{h h} / P_{d d}$ spectral ratio, a reduced standard deviation of ellipse orientation angle and the ellipticity and more linear polarization, as compared with the seismically quiet background. Finally, the direction finding based on the analysis of the total field and its pulsed component has also been performed. See the details in Schekotov et al. (2007, 2008).

\subsection{Fractal analysis}

This fractal analysis is one of physical signal processing methods in the sense that the nonlinear process taking place near the EQ hypocenter (i.e. self-organized criticality) can be studied as a change in fractal dimension and in fractal properties by means of the fractal analysis (Hayakawa and Ida, 2008).

The fractal analysis has been applied to different EQ events. This fractal analysis was, for the first time, applied to the 1993 Guam EQ event, in which they measured the slopes of frequency spectra to deduce the fractal dimension (Hayakawa et al., 1999). This fractal result could support the occurrence of seismogenic ULF emissions, and also it could provide us with the nonlinear self-organizing process in the lithosphere. The fractal properties for the $2000 \mathrm{Izu}$ islands EQ swarm was studied by Gotoh et al. (2004), Smirnova et al. (2004) and Ida et al. (2005), and Ida and Hayakawa (2006) have studied the monofractal and multi-fractal analyses for the 2003 Guam EQ in Table 1. These fractal analyses are found to give a further support to the presence of seismogenic ULF emission and to be useful in investigating the nonlinear process of the lithosphere. This fractal analysis has been utilized for the analysis of different seismogenic effects (e.g., Eftaxias et al., 2002).

\section{Characteristics of seismogenic ULF emissions and generation mechanism}

A large number of papers on seismogenic ULF emissions have been published since the famous EQs such as Spitak, Loma Prieta, Guam, and in this paper we have mainly reviewed our published results. We can summarize the characteristics of seismogenic ULF emissions based on not only our results, but also others.

1) ULF electromagnetic emissions take place as a precursor to a relatively large EQ. The sensitive distance $(R)$ is $70-80 \mathrm{~km}$ for EQs with magnitude $(M)$ 6.0 , and about $100 \mathrm{~km}$ for $M 7.0$. The empirical threshold of detection of seismogenic ULF emissions in Figure 2 is given by $0.025 R \leq M-4.5$. 
2) The ULF emissions for large EQs (with $M \geq 6.0$ ), seem to exhibit a typical temporal evolution. First of all, we have a first peak one month to a few weeks before the EQ, followed by a quiet period about one week before the EQ and a significant increase in amplitude a few days before the EQ. A slow relaxation is seen after the EQ.

3) The amplitude of those seismogenic ULF emissions is found to range from $0.1 \mathrm{nT}$ to a few $\mathrm{nT}$. However, their frequency spectra are not well understood, that is, what is the predominant frequency? Recent studies indicate the importance of the frequency of $10 \mathrm{mHz}$ (period of $100 \mathrm{~s}$ ).

4) There exist a few exceptions to the empirical threshold, including the cases of the 2004 NiigataChuetsu EQ, the 2004 Sumatra EQ. The common property for these two EQs is their shallow depth $(\sim 10 \mathrm{~km})$. This can be understood in terms of the following hypothesis. Once the ULF emission is generated at shallow depths or just around the ground surface, they can propagate in the Earth-ionosphere waveguide over long distances as the quasi-TEM mode (Ohta et al., 2007).

We finally review the generation mechanism of those seismogenic ULF emissions. It has been proposed that the ULF emission is generated by a mechanism which requires the charge separation (as an ensemble of small antennas) due to microfracturing by the stress change in the focal region before the EQ (Molchanov and Hayakawa, 1995). According to their theoretical estimate, the ULF emission can be detected within $70 \mathrm{~km}$ for M6.0 and $100 \mathrm{~km}$ for M7.0 (Molchanov et al., 1995). This theoretical estimate seems to be in good agreement with the above-mentioned experimental threshold in Figure 2. When the radio emission is generated at the source region, it should be wide-banded. However, the higher-frequency components decay during the propagation in the lithosphere, which results in the possible detection of ULF emissions near the Earth's surface. Another possible mechanism is electro-kinetic effect (Fenoglio et al., 1995). This mechanism is due to the fluid diffusion in the porous and fractured ground, and the electro-kinetic effect is originated due to appearance of an electric double layer formed at the solid/liquid interface during the liquid movement. We cannot say, at the moment, which one of these two representative mechanisms is more probable as the generation mechanism of seismogenic ULF emissions (Molchanov and Hayakawa, 2008). Then, we comment on another aspect of the preparation process of EQs. During this preparation phase, the lithosphere is known to exhibit a self-organized criticality phenomenon. That is, we expect the microfracturing in the focal region due to the stress increase, followed by the growth and coalescence of microcracks. This process is thought to be involved in the generation of ULF-emissions.

\section{Concluding remarks}

Different from the classification of seismogenic measurements in the section of Introduction, there is an alternative way to classify seismogenic observations: (1) local and (2) integrated measurements (e.g., Molchanov and Hayakawa, 2008). The observation of seismogenic ULF emissions belongs to the first category, and the characteristic property of the local measurement is that the emissions in any frequency range can be detected only when our observing station happens to be close to the EQ epicenter. This is the reason why we have only 20-30 events as summarized in Figure 2. On the other hand, one typical example of the integrated measurement is the ionospheric perturbations by means of subionospheric VLF/LF signals. That is, any EQs close to the great circle path from the transmitter to the receiver, can have significant effects on the signal at the receiver, so that it is rather easy for us to accumulate the number of events. In fact we have just established a significant statistical correlation between the VLF/LF propagation anomaly (ionospheric perturbation) and EQs on the basis of many-years data (Hayakawa et al., 2010).

It is likely that distinct ULF emissions take place in the lithosphere in association with EQs, even though there have been published a few papers which may cast a question to the existence of seismogenic ULFemissions (Campbell, 2009; Thomas et al., 2009a, b). The primary importance as for seismogenic ULF emissions is to increase the number of convincing events, though Fraser-Smith (2009) has mentioned that all of the three events in Table 1 are reliable enough to suggest the presence of seismogenic ULF emissions. For this purpose as well, sophisticated signal processings are highly required as discussed in this review in order to identify weak signals embedded in the noise. The definite distinction from man-made noise, geomagnetic effects, other noises, etc. is only possible by means of sophisticated signal processings as shown in this review, which would give a definite answer to some papers against the seismogenic ULF emissions. Having established different-scale networks in Japan ((1) Kanto (Tokyo) district, (2) central part of Japan (Chubu dis- 
trict) and (3) nation-wide) would enable us to accumulate the number of events as well. The simultaneous use of data at multiple stations would make it possible to investigate the spatial and temporal scales of those seismogenic ULF emissions, and also to determine the source region of a future EQ by means of direction finding (especially being important from the standpoint of EQ prediction).

The accumulation of much more convincing events (not only the presence, but also their characteristics) would lead us to the elucidation of the generation mechanism of seismogenic ULF emissions (microfracturing, electro-kinetic effect or so).

Finally, it is also desirable to compare the ULF seismogenic emission in this review with other seismogenic phenomena in different frequency ranges and in different region (atmosphere and ionosphere) and to perform the coordinated analysis with the seismic and geological data for the complete understanding of electromagnetic phenomena associated with EQs.

Acknowledgements A considerable part of the works was carried out in the frameworks of Frontier Projects by NASDA and RIKEN to which we are grateful, and thanks are also due to NICT (National Institute of Information and Communications Technology) ( $\mathrm{R}$ and $\mathrm{D}$ promotion scheme funding international joint research) for its financial support. Finally, we would like to express our sincere thanks to Prof. Y. Kopytenko (IZMIRAN) for his collaboration.

\section{References}

Ando Y, Maltsev P, Sukhynyuk A, Goto T, Yamauchi T, Hobara Y, Sekiguchi M, Ikegami Y, Sera M, Korepanov $\mathrm{V}$ and Hayakawa M (2005). New ELF observation system at Moshiri, Japan and assessment of acquired data. $J$ Atmos Electr 25(1): 29-39.

Campbell W H (2009). Natural magnetic disturbance fields, not precursors. J Geophys Res 114: A05307, doi:10.1029/2008JA013932.

Dudkin F, Rawat G, Arora B R, Korepanov V, Leotyeva O and Sharma A K (2010). Application of polarization ellipse technique for analysis of ULF magnetic fields from two distant stations in Koyna-Warna seismoactive region, West India. Natural Hazards Earth System Sci 10: $1-10$.

Eftaxias K, Kapiris P, Dologlou E, Kopanas J, Bogris N, Antonopoulons G, Peratzakis A and Hadjicontis V (2002). EM anomalies before the Kozani earthquake: A study of their behavior through laboratory experiments. Geophys Res Lett 29, doi:10.1029/2001GL013786.
Fenoglio M A, Johnston M J S and Byerlee J D (1995). Magnetic and electric fields associated with changes in high pore pressure in fault zones: Application to the Loma Prieta ULF emissions. J Geophys Res 100: $12951-$ 12958.

Fraser-Smith A C (2009). The ultralow-frequency magnetic fields associated with and preceding earthquakes. In: Hayakawa M ed. Electromagnetic Phenomena Associated with Earthquakes. Transworld Research Network, Trivandrum (India), Chapter 1, 1-20.

Fraser-Smith A C, Bernardi A, McGill P R, Ladd M E, Helliwell R A and Villard O G Jr. (1990). Low-frequency magnetic field measurements near the epicenter of the $M_{\mathrm{S}} 7.1$ Loma Prieta earthquake. Geophys Res Lett 17: 1465-1 468.

Gotoh K, Akinaga Y, Hayakawa M and Hattori K (2002). Principal component analysis of ULF geomagnetic data for Izu islands earthquakes in July 2000. J Atmos Electr 22: $1-12$.

Gotoh K, Hayakawa M, Smirnova N A and Hattori K (2004). Fractal analysis of seismogenic ULF emissions. Phys Chem Earth 29: 419-424.

Hata M, Ohta K, Izutsu J, Takumi I, Fujii T, Sato T, Yahashi S and Watanabe N (2010). Detecting electromagnetic-wave precursor of earthquakes. $J$ Atmos Electr 30(1): 13-36.

Hattori K (2004). ULF geomagnetic changes associated with large earthquakes. Terr Atmos Ocean Sci 15: 329-360.

Hattori K, Akinaga Y, Hayakawa M, Yumoto K, Nagao $\mathrm{T}$ and Uyeda S (2002). ULF magnetic anomaly preceding the 1997 Kagoshima earthquakes. In: Hayakawa $\mathrm{M}$ and Molchanov O A eds. Seismo Electromagnetics: Lithosphere-Atmosphere-Ionosphere Coupling. TERRAPUB, Tokyo, 19-28.

Hattori K, Takahashi I, Yoshino C, Isezaki N, Iwasaki H, Harada M, Korepanov K, Molchanov O, Hayakawa M, Noda Y, Nagao T and Uyeda S (2004). ULF geomagnetic field measurements in Japan and some recent results associated with Iwateken Nairiku Hokubu earthquakes in 1998. Phys Chem Earth 29(4-9): 481-494.

Hayakawa M (2006). Measuring techniques of electromagnetic phenomena associated with earthquakes and latest results. Inst Electr Inform Comm Engrs Japan J89-B: 1036-1045 (in Japanese).

Hayakawa M ed. (1999). Atmospheric and Ionospheric Electromagnetic Phenomena Associated with Earthquakes. Terra Scientific Pub. Comp., Tokyo, 996pp.

Hayakawa M and Fujinawa Y eds. (1994). Electromagnetic Phenomena Related to Earthquake Prediction. Terra Scientific Pub. Comp., Tokyo, 677pp.

Hayakawa M and Hattori K (2004). Ultra-low-frequency electromagnetic emissions associated with earthquakes: A review. Inst Electr Engrs, Japan, Trans Fundamentals and Materials 124: 1101-1 108. 
Hayakawa M and Hobara Y (2010). Current status of seismoelectromagnetics for short-term earthquake prediction. Geomatics, Natural Hazards and Risk 1(2): 115-155.

Hayakawa M and Ida Y (2008). Fractal (mono- and multi-) analysis for the ULF data during the 1993 Guam earthquake for the study of prefracture criticality. Current Development in Theory and Applications of Wavelets 2(2): 159-174.

Hayakawa M and Molchanov O A eds. (2002). Seismo Electromagnetics: Lithosphere-Atmosphere-Ionosphere Coupling. TERRAPUB, Tokyo, 477pp.

Hayakawa M and Ohta K (2006). The importance of direction finding technique for the study of VLF/ELF sferics and whistlers. IEEJ Trans Fundamentals and Materials 126(2): $65-70$.

Hayakawa M, Hattori K and Ohta K (2007). Monitoring of ULF (ultra-low-frequency) geomagnetic variations associated with earthquakes. Sensors 7: 1 108-1 122.

Hayakawa M, Itoh T and Smirnova N (1999). Fractal analysis of ULF geomagnetic data associated with the Guam earthquake on August 8, 1993. Geophys Res Lett 26(18): 2797-2 800.

Hayakawa M, Kasahara Y, Nakamura T, Muto F, Horie T, Maekawa S, Hobara Y, Rozhnoi A A, Solivieva M and Molchanov O A (2010). A statistical study on the correlation between lower ionospheric perturbations as seen by subionospheric VLF/LF propagation and earthquakes. $J$ Geophys Res 115: A09305, doi:10.1029/2009JA015143.

Hayakawa M, Kawate R, Molchanov O A and Yumoto K (1996). Results of ultra-low-frequency magnetic field measurements during the Guam earthquake of 8 August 1993. Geophys Res Lett 23: 241-244.

Hobara Y, Hayakawa M, Williams E, Boldi R and Downes E (2006). Location and electrical properties of spriteproducing lightning from a single ELF site. In: Fuellekrug M, Mareev E A and Rycroft M J eds. Sprites, Elves and Lightning Discharges. Springer, Dordrecht, 211-235.

Ida Y and Hayakawa M (2006). Fractal analysis for the ULF data during the 1993 Guam earthquake to study prefracture criticality. Nonlinear Processes Geophys 13: 409-412.

Ida Y, Hayakawa M, Adalev A and Gotoh K (2005). Multifractal analysis for the ULF geomagnetic data during the 1993 Guam earthquake. Nonlinear Processes Geophys 12: 157-162.

Ida Y, Yang D, Li Q, Sun H and Hayakawa M (2008). Detection of ULF electromagnetic emissions as a precursor to an earthquake in China with an improved polarization analysis. Natural Hazards Earth System Sci 8: 775-777.

Ismaguilov V S, Kopytenko Yu A, Hattori K and Hayakawa M (2002). Variations of phase velocity and gradient values of ULF geomagnetic disturbances connected with the Izu strong earthquakes. Natural Hazards Earth System
Sci 20: 1-5.

Koons H C, Roeder J L, Hobara Y, Hayakawa M and Fraser-Smith A C (2002). Statistical analysis of the data from the ULF sensors at Seikoshi station. In: Hayakawa M and Molchanov O A eds. Seismo Electromagnetics: Lithosphere-Atmosphere-Ionosphere Coupling. TERRAPUB, Tokyo, 29-39.

Kopytenko Yu A, Ismaguilov V S and Nikitina L V (2009). Study of local anomalies of ULF magnetic disturbances before strong earthquakes and magnetic fields induced by tsunami. In: Hayakawa M ed. Electromagnetic Phenomena Associated with Earthquakes. Transworld Research Network, Trivandrum (India), Chapter 2, 21-40.

Kopytenko Yu A, Ismaguilov V S, Hattori K and Hayakawa M (2002). Monitoring of the VLF electromagnetic disturbances at the station network before EQ in seismic zones of Izu and Chiba peninsulas. In: Hayakawa $\mathrm{M}$ and Molchanov O A eds. Seismo Electromagnetics: Lithosphere-Atmosphere-Ionosphere Coupling. TERRAPUB, Tokyo, 11-18.

Kopytenko Yu A, Matiashvili T G, Voronov P M, Kopytenko E A and Molchanov O A (1993). Detection of ultra-low-frequency emissions connected with the Spitak earthquake and its aftershock activity based on geomagnetic pulsations data at Dusheti and Vardzia observatories. Phys Earth Planet Inter 77: 85-95.

Molchanov O A and Hayakawa M (1995). Generation of ULF electromagnetic emissions by microfracturing. Geophys Res Lett 22: 3091-3094.

Molchanov O A and Hayakawa M (2008). Seismo Electromagnetics and Related Phenomena: History and Latest Results. TERRAPUB, Tokyo, 189pp.

Molchanov O A, Hayakawa M and Rafalsky V A (1995). Penetration characteristics of electromagnetic emissions from an underground seismic source into the atmosphere, ionosphere and magnetosphere. J Geophys Res 100: 1691-1 712 .

Molchanov O A, Kopytenko Y A, Voronov P M, Kopytenko E A, Matiashvili T G, Fraser-Smith A C and Bernadi A (1992). Results of ULF magnetic field measurements near the epicenters of Spitak $\left(M_{\mathrm{S}}=6.9\right)$ and Loma Prieta $\left(M_{\mathrm{S}}=7.1\right)$ earthquakes: Comparative analysis. Geophys Res Lett 19: 1495-1 498.

Ohta K, Watanabe N and Hayakawa M (2005). The observation of ULF emissions at Nakatsugawa in possible association with the 2004 Mid Niigata Prefecture earthquake. Earth Planets Space 57: 1003-1008.

Ohta K, Watanabe N and Hayakawa M (2007). The observation of ULF emissions at Nakatsugawa, Japan, in possible association with the Sumatra earthquake. Int'l $J$ Remote Sensing 28: 3121-3131.

Schekotov A Y, Molchanov O A, Hayakawa M, Fedorov E N, Chebrov V N, Sinitsin V I, Gordeev E E, Andreevsky S E, Belyaev G G, Yagova N V, Gladishev V A and Baran- 
sky L N (2008). About possibility to locate an EQ epicenter using parameters of ELF/ULF preseismic emission. Natural Hazards Earth System Sci 8: 1237-1 242.

Schekotov A Y, Molchanov O A, Hayakawa M, Fedorov E N, Chebrov V N, Sinitsin V I, Gordeev E E, Belyaev G G and Yagova N V (2007). ULF/ELF magnetic field variations from atmosphere induced by seismicity. Radio Sci 42: RS6S90, doi:10.1029/2005RS003441.

Smirnova N, Hayakawa M and Gotoh K (2004). Precursory behavior of fractal characteristics of the ULF electromagnetic fields in seismic active zones before strong earthquakes. Phys Chem Earth 29: 445-451.

Takahashi I, Hattori K, Harada M, Yoshino C and Isezaki N (2007). Anomalous geo-electrical signals observed at southern Boso peninsula. Ann Geophys (Italy) 50: 123135.

Thomas J N, Love J J and Johnson M J S (2009a). On the reported magnetic precursor of the 1989 Loma Prieta earthquakes. Phys Earth Planet Inter 173: 207-215, doi:10.1016/J.pepi.2008.11.014.

Thomas J N, Love J J, Johnson M J S and Yumoto K (2009b). On the reported magnetic precursor of the 1993 Guam earthquake. Geophys Res Lett 36: L16301, doi:10.1029/2009GL039020.

Uyeda S, Nagao T and Kamogawa M (2009). Shortterm earthquake prediction: Current state of sesimoelectromagnetics. Tectonophysics 470: 205-213. 